\title{
Fish assemblages and diversity in three tributaries of the Irrawaddy River in China: changes, threats and conservation perspectives
}

\author{
M.-L. Yang ${ }^{1,2}$, W.-S. Jiang ${ }^{3, \star}$, W.-Y. Wang ${ }^{4}$, X.-F. Pan $^{3}$, D.-P. Kong ${ }^{5}$, F.-H. Han ${ }^{1}$, X.-Y. Chen ${ }^{3,6}$ \\ and J.-X. Yang ${ }^{3}$ \\ 1 Yunnan Provincial Appraisal Center for Environmental Engineering, Kunming 650032, P.R. China \\ 2 College of Earth and Environment Sciences, Lanzhou University, Lanzhou 730000, P.R. China \\ 3 State Key Laboratory of Genetic Resources and Evolution, Kunming Institute of Zoology, Chinese Academy of Sciences, Kunming 650223, \\ P.R. China \\ ${ }^{4}$ POWERCHINA Kunming Engineering Corporation Limited, Kunming 650051, P.R. China \\ 5 Yunnan Key Laboratory of Pollution Process and Management of Plateau Lake-Watershed, Yunnan Institute of Environmental Science, \\ Kunming China International Research Center for Plateau Lake, Kunming 650034, P.R. China \\ ${ }^{6}$ Southeastern Asia Biodiversity Research Institute, Chinese Academy of Sciences, Yezin, Nay Pyi Taw 05282, Myanmar
}

Received October 25, 2015 - Revised December 3, 2015 - Accepted December 4, 2015

\begin{abstract}
Incompletely known fish assemblages and species diversity are substantial obstacles in fish conservation, particularly when their aquatic habitats are under threat due to rapid human-induced changes. Fish assemblages and diversity in three tributaries of the upper Irrawaddy River in China (the Dulong, Daying and Ruili rivers) were examined based on field collections and literature resources. The newly compiled fish assemblage recorded 85 species (in 8 orders, 20 families and 51 genera) distributed in the upper Irrawaddy. The fish compositions in the Daying (67 species, 44 genera, 19 families, 7 orders) and Ruili rivers (65 species, 44 genera, 19 families, 8 orders) were more similar to each other and more speciose than that in the Dulong River (14 species, 10 genera, 4 families, 3 orders). Two indices of taxonomic diversity (the average taxonomic distinctness $\left(\Delta^{+}\right)$, and the variation in taxonomic distinctness $\left(\Lambda^{+}\right)$) were used to discriminate four collections spanning a ten-year period. A decrease in taxonomic diversity and an increase in unevenness of the fish assemblages were found in both the Daying River and Ruili rivers, which indicated that the impacts were accumulated gradually during this decade, when dams and the spread of non-native species were major threats. Comparatively speaking, the Dulong River is still in a near-natural state, and thus the fish community has experienced less disturbance. In situ conservation (nature reserves and tributary protection) and ex situ conservation (artificial propagation and release) should be combined and managed to promote fish conservation in the future.
\end{abstract}

Key-words: Freshwater fish / taxonomic diversity / threats / dams / Irrawaddy

Résumé - La diversité et les communautés de poissons dans trois affluents de la rivière Irrawaddy en Chine : changements, menaces et perspectives de conservation. Les assemblages de poissons et leur diversité spécifique incomplètement connus sont d'importants obstacles à la conservation des poissons, en particulier lorsque leurs habitats aquatiques sont menacés en raison des rapides changements induits par l'homme. Les assemblages de poissons et leur diversité dans trois affluents de la rivière Irrawaddy supérieure en Chine (les rivières Dulong, Daying et Ruili) ont été étudiés sur la base de collectes sur le terrain et des ressources de la littérature. L'assemblage de poissons nouvellement compilé comporte 85 espèces ( 8 ordres, 20 familles et 51 genres) répartis dans l'Irrawaddy supérieure. Les compositions de poissons dans les rivières Daying (67 espèces, 44 genres, 19 familles, 7 ordres) et Ruili (65 espèces, 44 genres, 19 familles, 8 ordres) sont plus semblables les uns aux autres et plus riches en espèces que dans la rivière Dulong (14 espèces, 10 genres, 4 familles, 3 ordres). Deux indices de diversité taxonomique (la taxonomique moyenne $\left(\Delta^{+}\right)$, et la variation de la distance taxonomique $\left(\Lambda^{+}\right)$) ont été utilisés pour discriminer quatre échantillonnages couvrant une période de dix ans. Une diminution de la diversité taxonomique et une augmentation des inégalités des assemblages de poissons ont été trouvées dans les deux rivières Daying et Ruili, ce qui indique que les impacts ont été accumulés progressivement au cours de cette décennie, lorsque les barrages et la propagation d'espèces non indigènes étaient les principales menaces. Comparativement parlant, la rivière Dulong est toujours dans un état proche du naturel, et donc

^ Corresponding author: jiangws@mail.kiz.ac.cn 
la communauté de poissons a connu moins de perturbations. La conservation in situ (réserve naturelle et protection de l'affluent) et la conservation ex situ (propagation artificielle et relâcher) devraient être combinées et gérées pour promouvoir la conservation des poissons à l'avenir.

Mots-clés : Poisson d'eau douce / diversité taxonomique / menace / barrage / Irrawaddy

\section{Introduction}

The status of many Asian freshwater fish species is incompletely known, suffering from misidentifications, taxonomic inaccuracies, and out-of-date records in national or local species inventories (Kottelat and Whitten, 1996). As a consequence, freshwater biodiversity is often ignored in development plans due to a lack of accurate and readily available information on the status and distribution of taxa (Allen et al., 2010). The current impediment of insufficient data should not be the reason, or justification, for preventing further losses, although undoubtedly the detailed assessment of the biodiversity in many regions is imperative (Dudgeon et al., 2006). Recent research showed that fish assemblages are sensitive to a broad range of stressors (e.g. Oberdorff et al., 2002), and thus can act as reliable indicators of aquatic ecosystem health (Rashleigh, 2004). Furthermore, many studies have indicated that escalating anthropogenic impacts on fish biodiversity have greatly stimulated the need for using full taxonomic inventories to understand the diversity patterns (Mora et al., 2008). Therefore, establishing accurate fish assemblage inventories is an elementary step in freshwater biodiversity conservation.

The Irrawaddy River is an international river that flows from north to south, mainly through Myanmar, with a small number of tributaries originating in China and India. The fish diversity of the Irrawaddy is supposed to be very high, for it flows through Indo-Burma, one of the eight greatest biodiversity hotspots on Earth (Myers et al., 2000). Fish diversity here has, in fact, been substantially underestimated (Ferraris and Britz, 2005) because large areas in Myanmar are still poorly known and have not yet been sampled (Allen et al., 2010). As far as we know, there is no comprehensive monograph of fish species present throughout the whole Irrawaddy River system.

The fish fauna in the upstream drainage network is one of the most fundamental elements in understanding and protecting the whole river biota (Dudgeon et al., 2006). There are three major upstream sub-drainages (hereafter called tributaries) of the Irrawaddy in China; that is, the Dulong River (upper reaches of N'mai River), Daying River (upper reaches of Taping River) and Ruili River (upper reaches of Shweli River) (Wu, 2010). Although the fishes of these areas were among the earliest examples of the ichthyofauna studied in Yunnan Province of China (e.g. Anderson, 1878; Day, 1869), it was only some 100 years later that the first comprehensive synopses of the fish fauna in this region were published (Chu and Chen, 1989, 1990). Since then, more than 20 new species have been described from this area, and more than 20 have been affected by taxonomic revision. However, no single study has provided a comprehensive review of these significant taxonomic changes in recent years. From a pragmatic aspect, this ecological area is undergoing a series of human-induced threats, such as habitat degradation, alien species invasion, and especially, the construction of hydropower projects. An attempt to predict the potential effects of these threats has greatly exacerbated the need for accurate information on the upper Irrawaddy ichthyofauna.

In this study, we compiled updated fish assemblages in the three tributaries of the Irrawaddy based on field collections spanning a ten-year period and extensive literature resources. Using this information, we aimed to (1) analyze the changes in fish diversity by historic collections; (2) discuss the main threats to fish diversity; and (3) provide recommendations for fish diversity conservation.

\section{Materials and methods}

\subsection{Description of the basin}

This study focused on the fish of the Irrawaddy River drainage area in China. The Irrawaddy River flows from north to south, mainly through Myanmar, originating from the confluence of the N'mai and Mali rivers and flowing in a relatively straight north-south direction before emptying through the Irrawaddy Delta into the Andaman Sea. Its drainage area is about $255081 \mathrm{~km}^{2}$, covering a large part of Myanmar. It has five major tributaries, which are, from north to south, the Taping River, Shweli River, Myitnge River, Mu River and Chindwin River (Wikipedia, 2014).

There are three upstream tributaries (Dulong River, Daying River and Ruili River) of the Irrawaddy flowing in southwest China (Figure 1). The Dulong River is $211.3 \mathrm{~km}$ long and covers a drainage area of $4327 \mathrm{~km}^{2}$, with $1200 \mathrm{~m}$ in fall head and an average rainfall of $4000 \mathrm{~mm}$ in the territory of Yunnan Province (Zhao and He, 1993). It originates from Chayu County in the Tibetan Autonomous Region, and flows from Gongshan County in Yunnan into Myanmar at Qinlangdang Village. The Daying River is $196.2 \mathrm{~km}$ long and covers a drainage area of $5859 \mathrm{~km}^{2}$, with $3345 \mathrm{~m}$ in fall head and an average rainfall of $2100 \mathrm{~mm}$. It originates from Guyong in Tengchong County of Yunnan, and flows from Tengchong, Lianghe and Yingjiang Counties into Myanmar at the junction of the Nanbang River. The Ruili River (also called Longchuan River) is $369.5 \mathrm{~km}$ long and covers a drainage area of $9743 \mathrm{~km}^{2}$, with $2523 \mathrm{~m}$ in fall head and an average rainfall of $1900 \mathrm{~mm}$. It originates from Mingguang (western Gaoligong Mountain) in Tengchong County of Yunnan, and flows from Tengchong, Longling, Lianghe, Longchuan, Luxi, Wanting and Ruili Counties into Myanmar at the junction of the Nanwan River (Wu, 2010). 

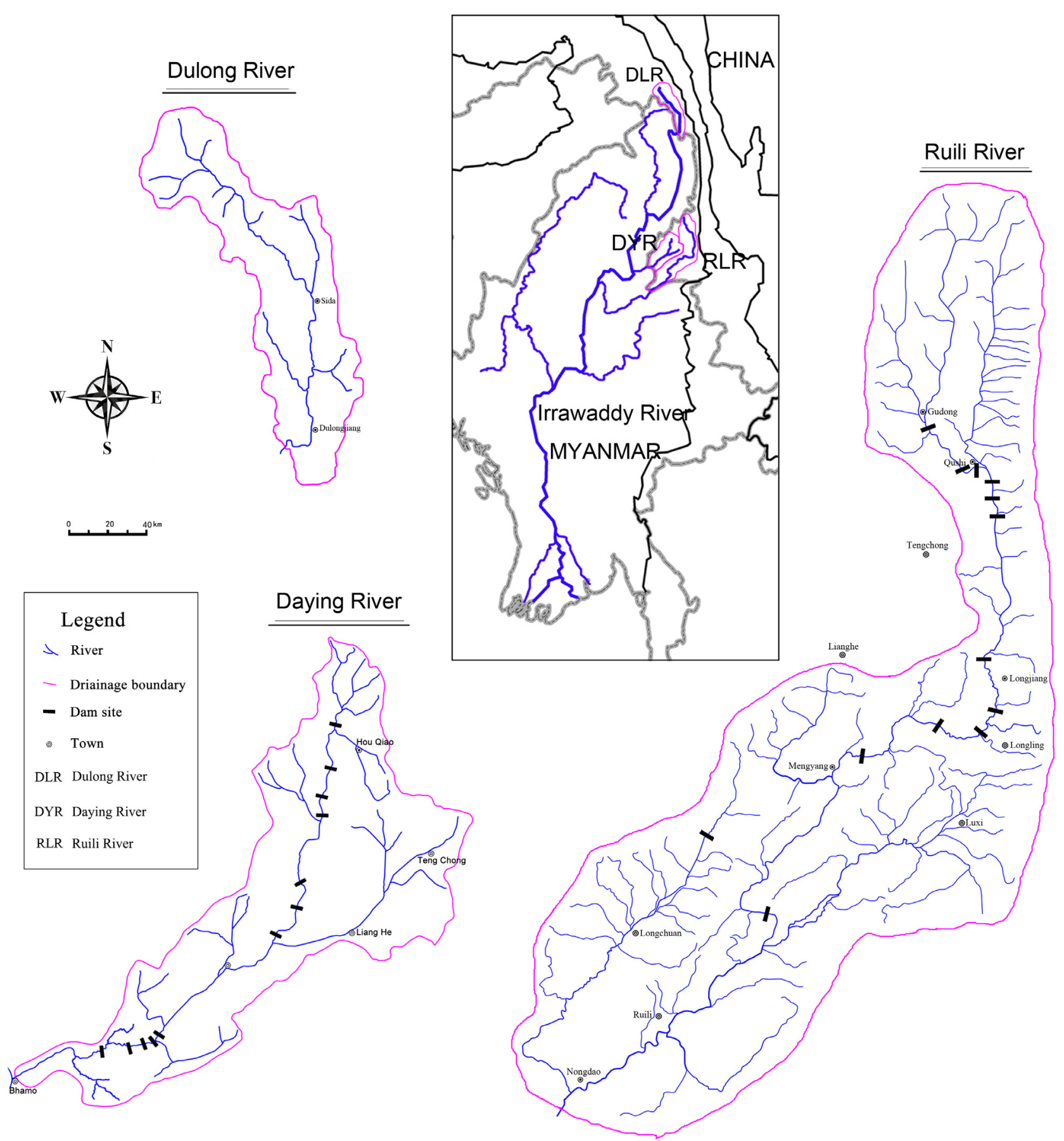

Fig. 1. Map of the locations of the three tributaries of the Irrawaddy in China (Dulong, Daying and Ruili rivers) and their dam sites.

\subsection{Identification and taxonomic updating}

We compiled and updated an inventory of fish species in the upper Irrawaddy drainage based on records in the existing literature (Chu and Chen 1989, 1990) and species described or revised after 1990. The information included: (1) descriptions of new species, such as Microrasbora microphthalma (Jiang et al., 2008), Tor yingjiangensis (Chen and Yang, 2004), Neolissochilus baoshanensis, Neolissochilus heterostomus (Chen and Yang, 2003; Chen et al., 1999),
Placocheilus dulongensis (Chen et al., 2012), Garra rotundinasus (Zhang, 2006), Garra bispinosa (Zhang, 2005), Garra tengchongensis (Zhang and Chen, 2002), Schizothorax leukus, Schizothorax heteri (Yang et al., 2013), Protonemacheilus longipectoralis (Yang and Chu, 1990), Schistura albirostris (Chen and Neely, 2012), Hemimyzon yinjiangensis (Chen, 2006), Pseudecheneis stenura (Zhang, 2006), Pseudecheneis brachyurus, Pseudecheneis gracilis (Zhou et al., 2008), Creteuchiloglanis macropterus (Ng, 2004; Zhou et al., 2011), Oreoglanis insignis (Ng and Rainboth, 2001), Dario dayingensis 
(Kullander and Britz, 2002), Mastacembelus strigiventus and Mastacembelus triolobus (Yang and Zhou, 2011); (2) taxonomic and nominal revisions, such as Danio albolineatus (Fang, 2000), Poropuntius margarianus (Chen and Yang, 2003), Labeo pierrei (Kottelat, 2001), Bangana devdevi (Zhang and Chen, 2006), Crossocheilus burmanicus (Kottelat, 2003; Su et al., 2000), Garra salweenica (Zhang, 2005), Lepidocephalichthys berdmorei, Lepidocephalichthys hasselti (Kottelat, 2001; Kottelat and Lim, 1992), Syncrossus berdmorei, Botia histrionica (Kottelat, 2004), Acanthocobitis botia, Schistura polytaenia, Schistura yingjiangensis, Schistura malaise, Schistura vinciguerrae, Schistura sikmaiensis (Kottelat, 1990) and Glyptothorax burmanicus ( $\mathrm{Ng}$ and Kottelat, 2008); and (3) new distribution records in these areas, such as Anguilla nebulosa (Pan and Zhou, 2004), Aspidoparia morar (Zhou et al., 2006), Puntius sophore, Puntius ticto (Chen et al., 1988; Shan, 2000), Heteropneustes fossilis (Yang et al., 2002) and Mastacembelus oatesii (Yang and Zhou, 2011). Higher-order classification follows (Nelson, 2006).

\subsection{Data sources}

Primary data on fish occurrences used in this study were based on the fish collections of the Kunming Institute of Zoology (KIZ), Chinese Academy of Sciences. Ichthyological surveys were conducted in the Ruili (September-October 2003; April-May 2006; November 2006; June 2014), Dulong (September-October 2004) and Daying (April-May 2006; July 2011; June 2012; October 2014) rivers.

Secondary data from published inventories were also used to obtain a more complete picture of the fish compositions in these areas, including fish collections from 1998 to 2002 in Daying River and Ruili River reported in Pan and Zhou (2004) and Zhou et al. (2006), from 2003 to 2006 in Ruili River by Jiang et al. (2010), and from 2004 and 2006 in Dulong River by Chen et al. (2006) and Xu et al. (2008).

To facilitate the diversity analyses, the integrated occurrence data from primary and secondary sources of the Daying River and Ruili River were classified into four temporal periods to maximize the number of sampling sites covering the length of the whole river. These collections in different periods were: DYR-1 (1998-2003), DYR-2 (2006), DYR-3 (2011-2012) and DYR-4 (2014) in Daying River; and RLR-1 (1998-2003), RLR-2 (2004-2006), RLR-3 (2006) and RLR-4 (2014) in Ruili River. The Dulong River was excluded in some diversity analyses due to insufficient collection information in the parallel temporal gradient.

\subsection{Data analysis}

Only native species were included in the diversity analyses because non-native species may have an unpredictable influence on the outcomes. Due to a lack of richness information from literature resources and uncontrolled sample sizes in different collections, only presence/absence data were used in this study. Despite the simplicity of presence/absence data, they provide reliable information for analyzing fish assemblage patterns (He et al., 2011).
Some diversity indices that are robust under variable or uncontrolled sampling effort were chosen to reflect variation in the structure of the fish assemblages along different gradients. Taxonomic diversity was one of these indices, that can be obtained by considering the taxonomic relationships among species. An assemblage comprising a group of closely related species must be regarded as less 'biodiverse' than an assemblage of the same number of more distantly related species, such as when they all belong to different phyla (Clarke and Warwick, 2001).

We used average taxonomic distinctness $\left(\Delta^{+}\right)$and variation in taxonomic distinctness $\left(\Lambda^{+}\right)$to measure taxonomic diversity, as per previous research (Clarke and Warwick, 1998, 2001). Here, $\Delta^{+}$is simply the mean number of steps up the hierarchy that must be taken to reach a taxonomic rank common to two species, computed across all possible pairs of species in an assemblage, with the formula:

$$
\Delta^{+}=2 \frac{\sum \sum_{i<j} \omega_{i j}}{s(s-1)},
$$

where $s$ is the number of species present, the double summation is over the set $(i=1, \ldots, s ; j=1, \ldots, s$, such that $i<j$ ), and $\omega_{i j}$ is the "distinctness weight" between species $i$ and $j$. Thus, if two species are congeneric, one step (speciesto-genus) is necessary to reach a common node in the taxonomic tree; if the two species belong to different genera but the same family, two steps will be necessary (species-to-genus, and genus-to-family); and so on, with the number of steps averaged across all species pairs (Mouillot et al., 2005). $\Delta^{+}$is the mean path length through the taxonomic tree connecting each pair of species; $\Lambda^{+}$is simply the variance of these pairwise path lengths and could be seen as an index of the "complexity" that reflects the unevenness of a hierarchical tree. It is defined as

$$
\begin{aligned}
& \qquad \Lambda^{+}=\frac{\sum \sum_{i \neq j}\left(\omega_{i j}-\bar{\omega}\right)^{2}}{s(s-1)}=\frac{\sum \sum_{i \neq j} \omega_{i j}^{2}}{s(s-1)}-\bar{\omega}^{2}, \\
& \text { where } \bar{\omega}=\frac{\sum \sum_{i \neq j} \omega_{i j}}{s(s-1)} \equiv \Lambda^{+} .
\end{aligned}
$$

These two metrics are not only independent of sample size (Clarke and Warwick, 1998, 2001), but also independent of each other, and can therefore reflect different aspects of relatedness (Gallardo et al., 2011). We used constant distances (path lengths) to weight each taxonomic level between genus, family, order, class and phylum (Heino et al., 2007).

The significance of departure from random expectation was determined by comparison of the measured value of $\Delta^{+}$ with 1000 random selections of species from the total species pool (Clarke and Warwick, 1998). A "funnel" distribution was constructed to represent the $95 \%$ confidence intervals for the null hypothesis: the fish list from one specific period was a random sample of the total fish list. The "Vegan" package (Oksanen et al., 2014) in R (R Development Core Team, 2012) was performed in the related analyses, where the "taxondive" function was used to calculate the distinctness metrics.

Furthermore, the $\beta$ diversity of different tributaries along a temporal gradient was also measured as the average distance from an individual sample to its group centroid on the basis of 
the Arrhenius species-area model (Anderson et al., 2006), and 999 permutations were used to test the significance of different groups. The functions "betadiver" and "betadisper" were used to calculate the $\beta$ diversity and homogeneity of different periods. We also used the "hclust" function to perform average linkage clustering to observe the relationships of these different collections among different sampling units.

\section{Results}

\subsection{Fish assemblage}

We identified a total of 85 fish species in the three tributaries of the upper Irrawaddy River drainage in China, which were distributed among 8 orders, 20 families and 51 genera. Among these were 76 indigenous species in 42 genera, and 9 non-native species in 9 genera. There were 67, 65 and 14 species distributed in the Daying, Ruili and Dulong rivers, respectively. Of these, 10, 7 and 3 species were restricted to these specific tributaries, and another 20 species were restricted to the whole Irrawaddy basin (Table 1).

The most species-rich orders in the basin were Cypriniformes and Siluriformes, accounting for $62.4 \%$ and $21.2 \%$ of the fish composition. Cyprinidae, Sisoridae and Nemacheilidae were the richest in genera and species in the basin, with 21 , 7 and 3 genera accounting for 44.7, 17.7 and $9.4 \%$ of the total species, respectively. Schizothorax in Cyprinidae, Schistura in Nemacheilidae and Glyptothorax in Sisoridae contained the highest number of species in the basin, with 8,6 and 5 species accounting for $9.41,7.06$ and $5.88 \%$ of the total species, respectively (Table 2).

A total of 67 species were identified in Daying River, belonging to 44 genera in 19 families and 7 orders. A total of 65 species were identified in Ruili River, belonging to 44 genera in 19 families and 8 orders. A total of 14 species were identified in Dulong River, belonging to 10 genera in 4 families and 3 orders (Table 1).

\subsection{Diversity and clusters}

The $\Delta^{+}$values for total assemblages varied among the three tributaries and were highest for Ruili River (69.58), followed by Daying River (67.27), and then Dulong River (64.75). Along the temporal gradient, $\Delta^{+}$ranged from 62.87 to 67.73 in Daying River and 62.19 to 67.56 in Ruili River, while $\Lambda^{+}$ ranged from 389.15 to 489.31 in Daying River and 342.15 to 428.47 in Ruili River. The scatterplot of $\Delta^{+}$against the four different temporal periods presented a linearly decreasing trend in both the Daying $\left(R^{2}=0.87\right)$ and Ruili rivers $\left(R^{2}=0.68\right)$; however, $\Lambda^{+}$against the temporal gradient presented a linearly increasing trend in Daying River $\left(R^{2}=0.65\right)$, but a slightly decreasing trend in Ruili River $\left(R^{2}=0.59\right)$ (Figure 2). The $\Delta^{+}$for fish species collected from all four different periods in both Daying River and Ruili River fell within the $95 \%$ limits of probability of the funnel for the random numbers from the regional species pool (Figure 3 ).

The average distance to the median (and thus $\beta$ diversity) along the temporal gradient of Daying River was a little lower than that of Ruili River, but was not significant from the permutation test $(F=0.20, P=0.67)$ (Figure 4a). Cluster analysis separated the different collections of the different tributaries other than via time sequences (Figure 4b). Species in Daying River and Ruili River were more closely related to each other than to those in Dulong River.

\section{Discussion}

\subsection{Fish assemblage of the Irrawaddy in China}

The updated fish assemblage of the Irrawaddy in China contained a total of 85 species, which was more than the 52 species previously reported (Chu and Chen, 1989, 1990). A total of 40 species $(47.1 \%)$ were restricted to the Irrawaddy River basin, indicating the high endemism of the SitangIrrawaddy ecoregion (Abell et al., 2008). However, our knowledge of the fish fauna in the whole Irrawaddy River is still incomplete and unclear, with 142 species currently recorded in this basin (Froese and Pauly, 2014). Although the Irrawaddy catchment area in China $\left(21911 \mathrm{~km}^{2}\right)$ only accounts for $8.6 \%$ of the whole Irrawaddy basin $\left(255081 \mathrm{~km}^{2}\right)$, the fish number in the former accounts for almost $60 \%$ of the latter. However, we cannot overlook that a substantial underestimation of Irrawaddy fish might exist because large areas of Myanmar are still poorly known and have not yet been sampled (Allen et al., 2010). The fish assemblage of the Irrawaddy in China reported here provides an important foundation to further understand the underestimated fish fauna of the Irrawaddy.

Daying River (67 species, 44 genera, 19 families, 7 orders) and Ruili River (65 species, 44 genera, 19 families, 8 orders) contained similar fish assemblages, and were more speciose than the Dulong River (14 species, 10 genera, 4 families, 3 orders). This was also revealed by cluster analysis (Figure $4 b$ ). The pattern of tributaries or river sections at higher altitude and latitude (Dulong River vs. Daying and Ruili rivers) containing fewer fish species is common in most major rivers running from the Qinghai-Tibet plateau. For example, the regional species richness in the Mekong River ranges from only 24 species in the Chinese headwaters far north to 484 species in the Mekong Delta (Ziv et al., 2012). Geological history (especially Himalayan orogeny) plays an important role in the speciation and current distribution pattern of fish inhabiting mountain streams around the Qinghai-Tibet plateau (Kottelat, 1989). The genus of Schizothorax, for example, has evolved into eight distinct species along the Dulong, Daying and Ruili rivers (Yang et al., 2013).

\subsection{Fish diversity and changes}

Comparison of samples obtained at different times can often be difficult (Zintzen et al., 2011). However, diversity indices that are independent of sampling sizes, such as $\Delta^{+}$and $\Lambda^{+}$, can provide reliable information for analyzing fish assemblage patterns, which is particularly important for historic (diffusely collected) species lists from different localities or regions (Clarke and Warwick, 1998). A previous study based on a long time-series dataset for bottom-dwelling fish from the 


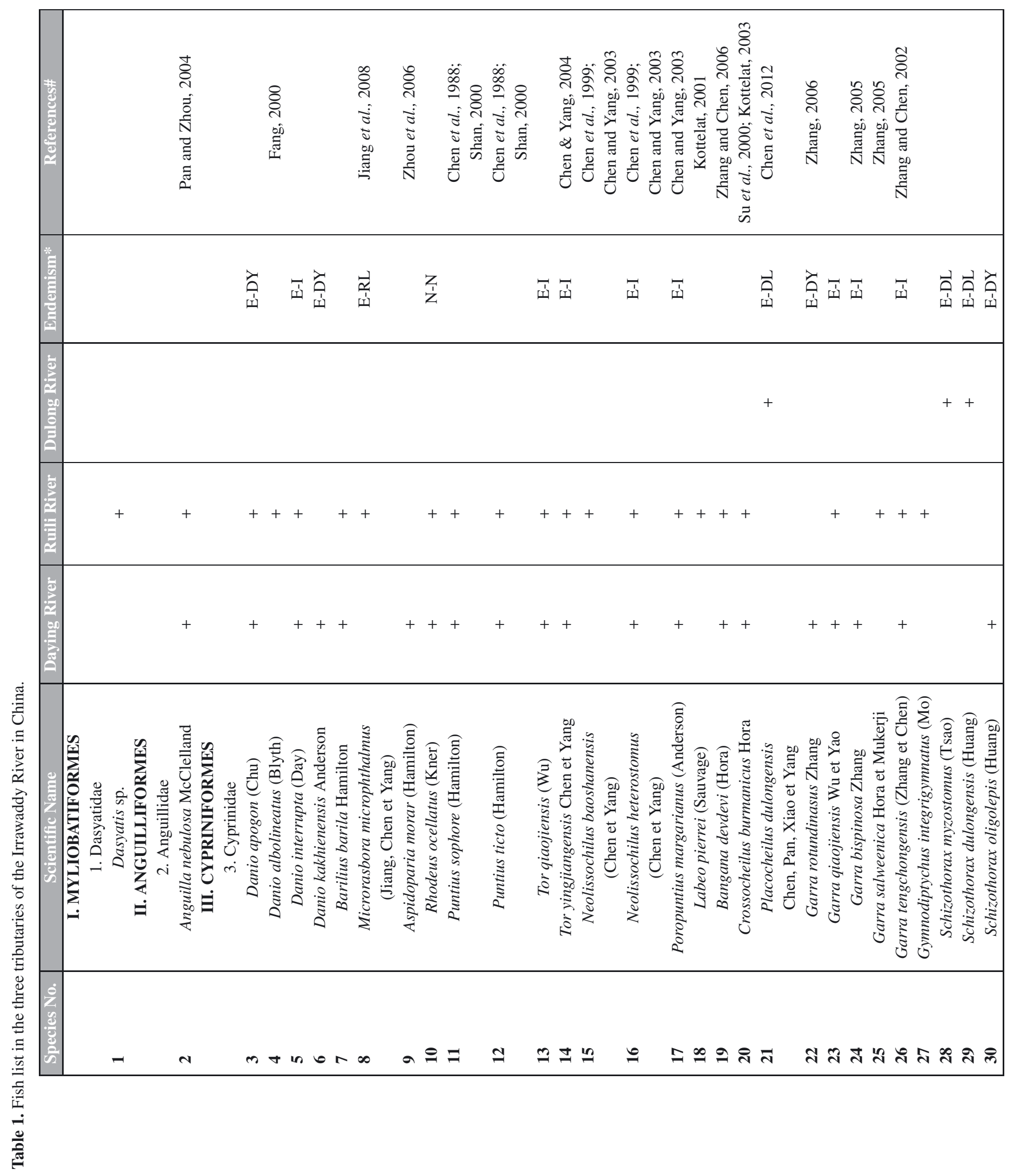




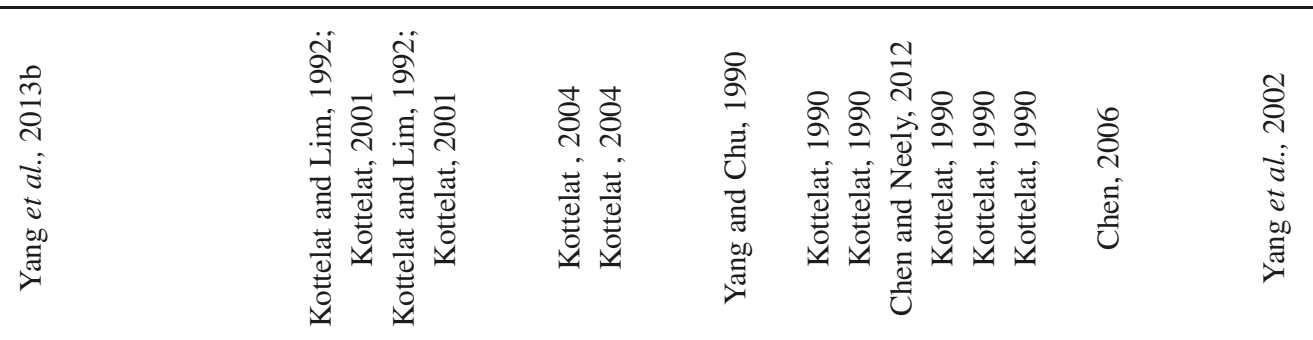

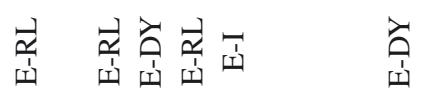

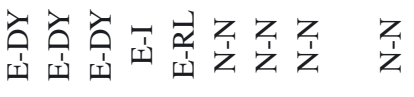




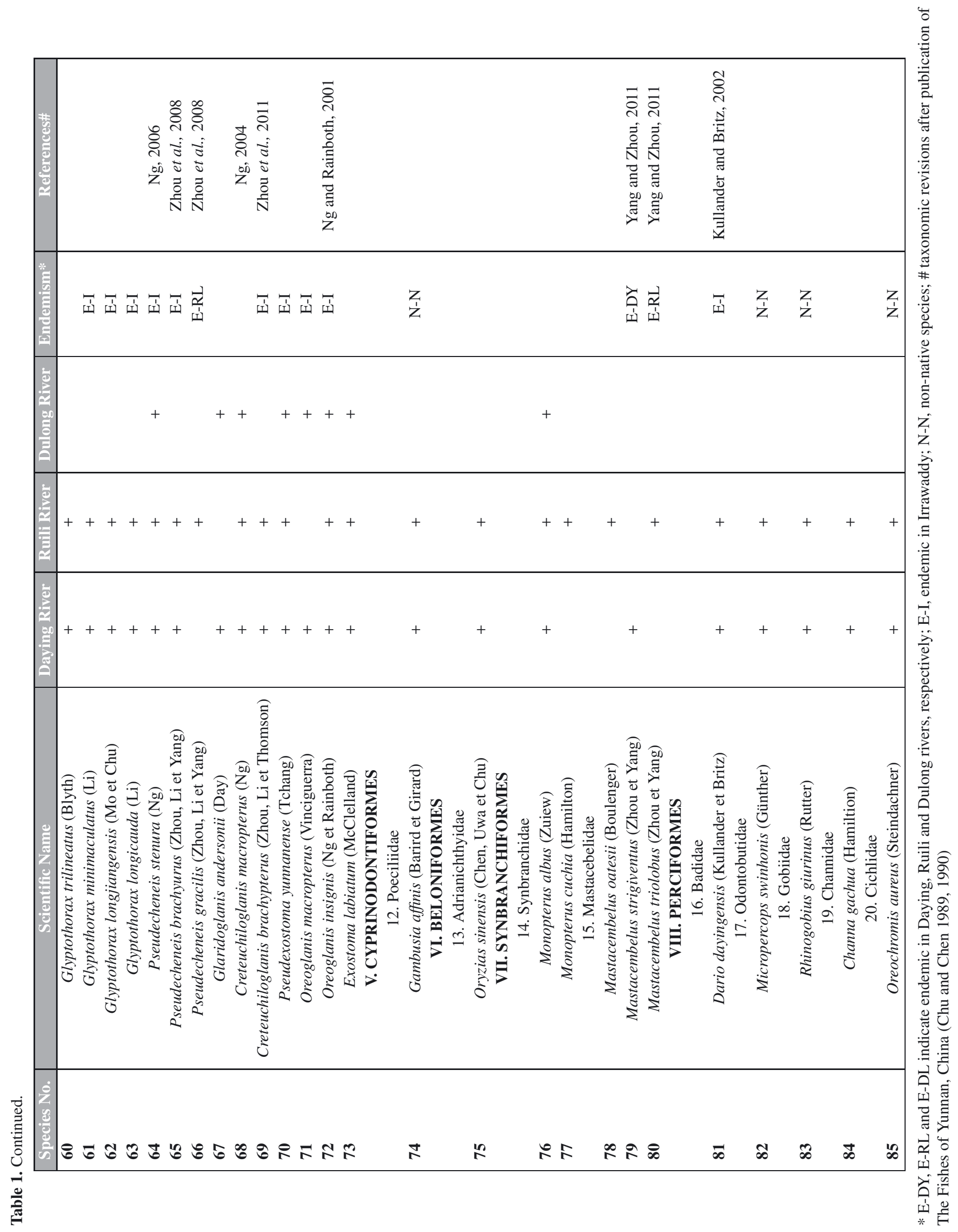


Table 2. Fish composition of the Irrawaddy River in China.

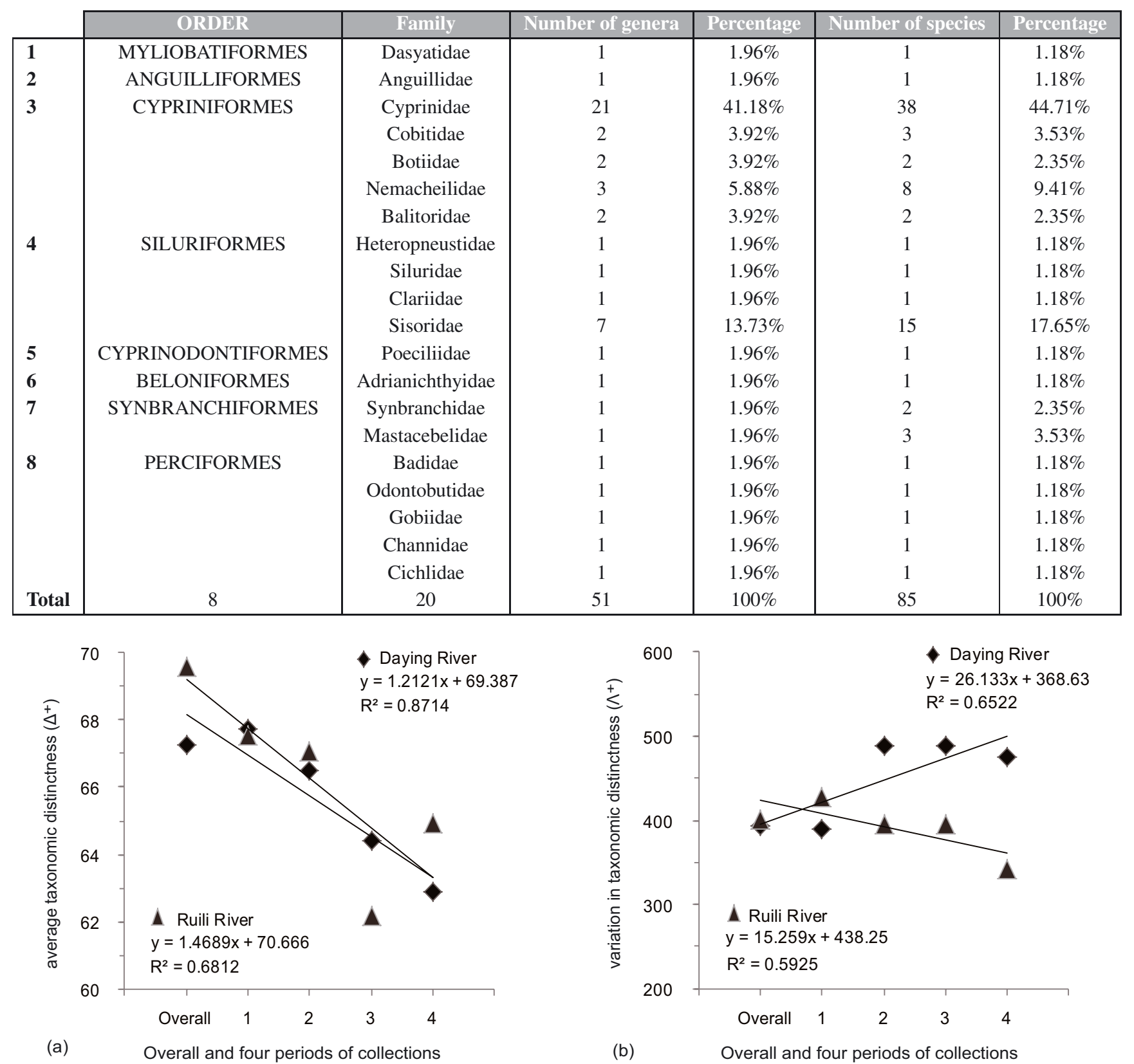

Fig. 2. Linear regression relationships between collections in different periods and two taxonomic diversity indices: (a) average taxonomic distinctness $\left(\Delta^{+}\right)$and $(b)$ variation in taxonomic distinctness $(\Lambda+)$.

northern North Sea showed that trends in taxonomic distinctness and diversity were identical to those shown by species richness from conventional indices (Hall and Greenstreet, 1998). In other words, more diverse (species-rich) areas always contain species that have a wider average taxonomic range than assemblages that are less diverse (Rogers et al., 1999).

The scatterplots of $\Delta^{+}$against different time periods showed similar decreasing trends in Daying River and Ruili River (Figure 2a), which indicated narrower taxonomic diversity in the fish collections from ten years ago to the present day. This kind of pattern has also been seen in other rivers in China (such as Dong River, a tributary of Pearl River, Zhang et al., 2014). In the Daying River drainage, Anguilla nebulosa, Hemimyzon yinjiangensis, Pterocryptis cochinchinensis and Dario dayingensis were only collected before 2003, but were no longer found in subsequent surveys. In the Ruili River drainage, Poropuntius margarianus and Gymnodiptychus integrigymnatus were collected before 2004 but have been absent since. The most commonly seen species in recent years have been dominated by native species in a few genera such as Danio, Schizothorax, Schistura and Glyptothorax and other 
M.-L. Yang et al.: Knowl. Manag. Aquat. Ecosyst. (2016) 417, 9
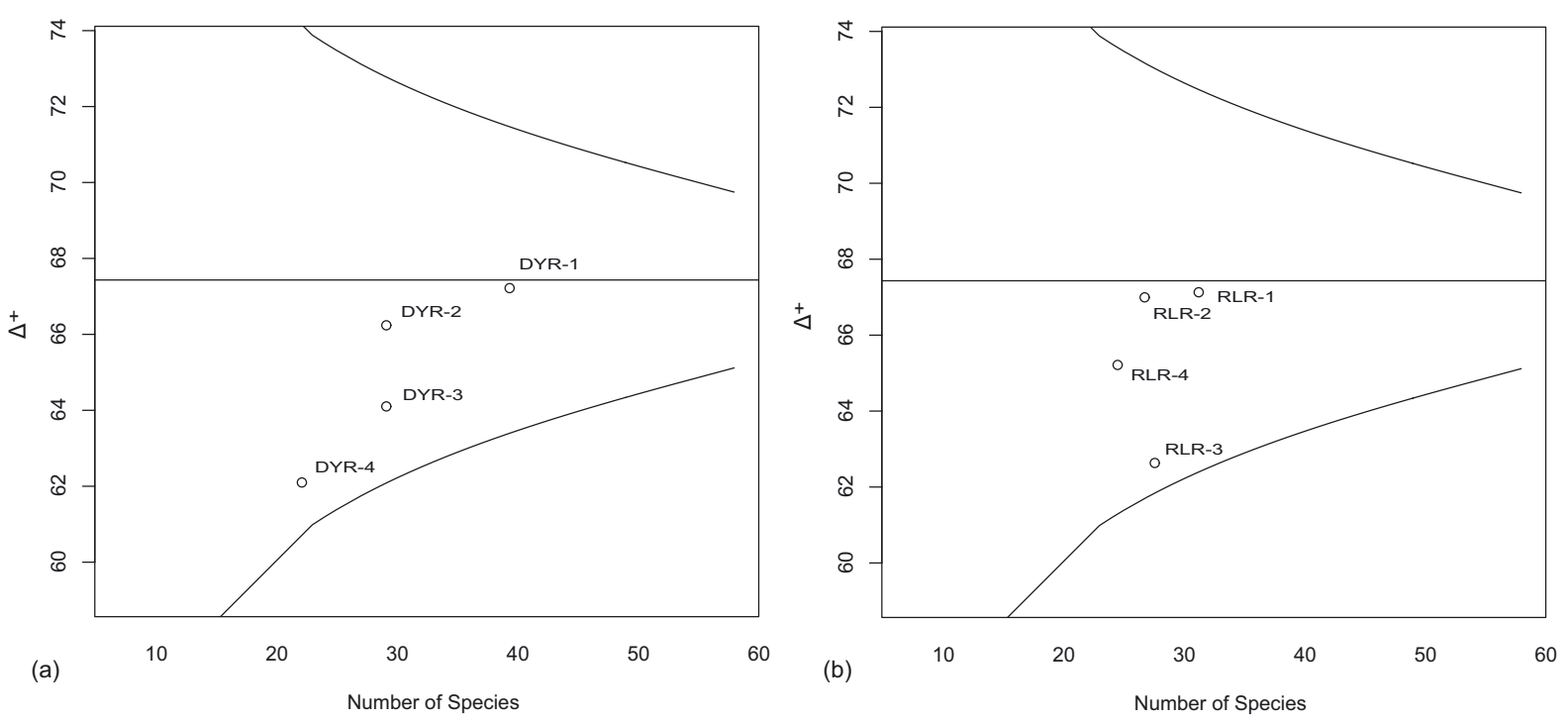

Fig. 3. Average taxonomic distinctness $\left(\Delta^{+}\right)$values for the four collection periods in (a) Daying River (DYR-1, 2, 3, 4) and (b) Ruili River (RLR-1, 2, 3, 4), plotted against the number of species on the $95 \%$ confidence funnel.

(a)

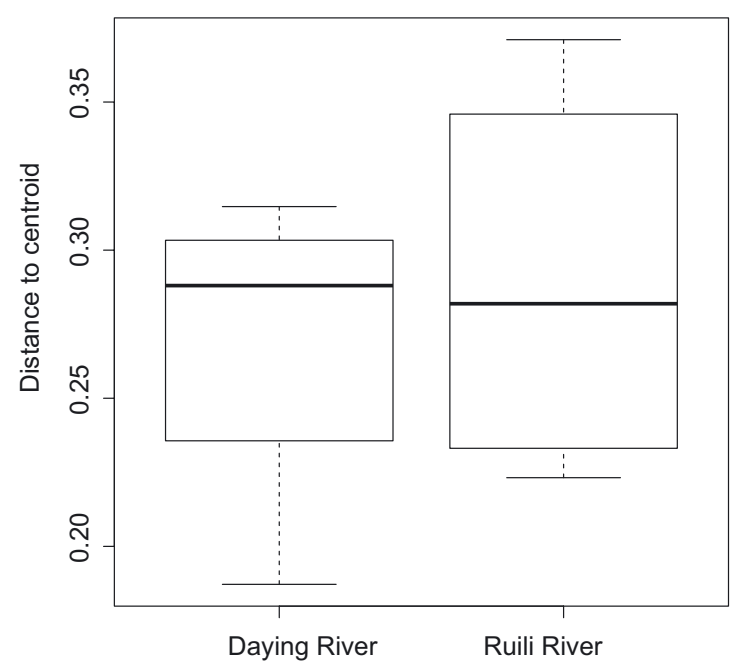

(b)

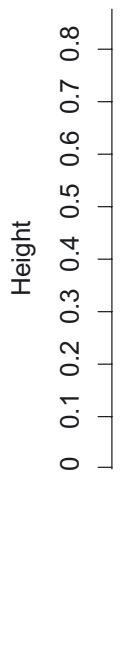

Cluster Dendrogram

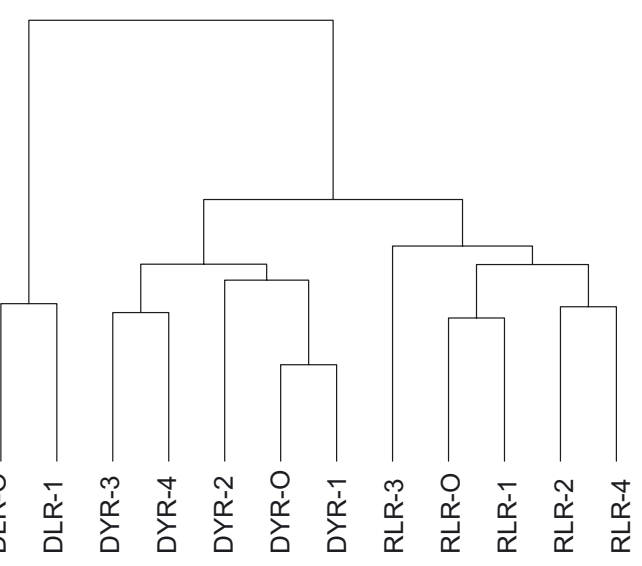

dis

hclust (", "average")

Fig. 4. (a) Beta diversity inferred from the average distance to the median of samples among four collection periods in the Daying and Ruili rivers. (b) Cluster analysis of different collections, including overall fish assemblages and different periods among Dulong River (DLR-O, 1), Daying River (DYR-O, 1, 2, 3, 4) and Ruili River (RLR-O, 1, 2, 3, 4).

non-native, but highly adaptive species such as Pseudorasbora parva, Gambusia affinis and Rhinogobius giurinus. Although the pattern of $\Delta^{+}$indicated that the average path length among species within these two rivers decreased along temporal gradients, each of the samples still fell into the random selections (95\% confidence intervals) from the regional species pool (Figure 3).

Because it considers variation in the evenness of taxonomic distribution, $\Lambda^{+}$is assumed to be a more dependable diversity index than $\Delta^{+}$and can relate resulting patterns to habitat conditions (Anu and Sabu, 2007). High $\Lambda^{+}$and lower taxonomic spread is usually a feature of degraded environments (Clarke and Warwick, 2001). As reflected in the scatterplots of $\Lambda^{+}$against different time periods (Figure 2b), Daying River had an increasing $\Lambda^{+}$trend along the temporal gradient, which might reflect increased habitat disturbance. However, this trend in Ruili River was relatively equivocal for a decreasing trend, albeit with a lower correlation coefficient, which mainly resulted from the sudden decrease of $\Lambda^{+}$in 2014 (RLR-4). It is possible that species with a unique taxonomic category may saturate the $\Lambda^{+}$values (Clarke and Warwick, 2001), such as Anguilla nebulosa (single genus, family and order), that was collected in Ruili River in 2014. This temporal turnover pattern of different tributaries was also primitively reflected from the $\beta$ diversity (average distance to median), with the value in Daying River being less than that in Ruili River 
(Figure 4a). In summary, decreasing taxonomic diversity and increasing unevenness of the fish assemblage were found in Daying River and Ruili River, which indicated that the impacts were accumulated gradually in the decade studied. The impacts in Daying River were much broader than those in Ruili River.

\subsection{Existing and potential threats}

Global freshwater biodiversity is undergoing significant impacts at higher rates and greater degrees than that of its marine and terrestrial counterparts (Dudgeon, 2011; Liermann et al., 2012). Major threats can be classified into overexploitation, water pollution, flow modification, destruction or degradation of habitat, and invasion by exotic species (Dudgeon et al., 2006). Different areas can suffer different dominant threats, such as the considerable water pollution in specific river sections of the upper Mekong (Kang et al., 2009) and overfishing in the floodplains of the lower Mekong (Allan et al., 2005). Among the three tributaries of the Irrawaddy in China, all threats mentioned above occur in the Daying and Ruili rivers. Given the relative absence of significant human development, however, the Dulong River is healthier than either the Daying or Ruili rivers. The Dulong River flows between Mt. Dandanglika in the west and Mt. Gaoligong in the east, and is isolated from human influence for more than six months (October to May) each year due to snowbound roads. Thus, it benefits from low disturbance and near-natural conditions, although recent investigations have found non-native fish species, such as common carp (Xu et al., 2008), in this river. In the Daying and Ruili rivers, however, the environmental impact from factors such as dams and the spread of nonnative fish is serious, as reflected in our fish diversity analyses.

\subsection{Dams}

Flow modification by dams constitutes a major threat to global freshwater species diversity (Vörösmarty et al., 2010). Nowhere has the Anthropocene transition become so apparent nor occurred so rapidly than in Asia, and nowhere reflects this so explicitly as China (Dudgeon, 2011). The implication of dams for fish diversity has been fully illustrated (Liermann et al., 2012); however, most studies have only focused on major rivers such as the Yangtze and Mekong (Dudgeon, 2011). Many tributaries affiliated with these major rivers are also undergoing intensive hydropower projects or planned construction, but seldom have they been studied. According to water resource development plans at the local (municipal) and provincial levels, Daying River is part of a 12-dam cascade and Ruili River is part of a 13-dam cascade. Most of these dams are already in operation for hydropower, while some are still under construction or being planned (Figure 1). Furthermore, many dams are being constructed or under planning on all major rivers or tributaries in Myanmar, and according to the Burma Rivers Network (http://burmariversnetwork.org/), most of these dams are on the Irrawaddy.

Dams obstruct the migration routes of diadromous or migrating fish, and transform free-flowing reaches into standing water where conditions are unsuitable for many native river fish (Limburg and Waldman, 2009). The only diadromous fish of the Irrawaddy River in China is Anguilla nebulosa, which is also distributed in rivers from east Africa to Indonesia (Froese and Pauly, 2014). This species is on the Yunnan provincial list of protected animals and evaluated as endangered (EN) on the Chinese Species Red List (Chen, 2013). Previously it was only collected in the Daying River before 2003, though we collected one individual in the middle reaches of the Ruili River in 2014. We cannot be certain that the Anguilla nebulosa population in the Ruili River can easily migrate anymore because this river is blocked by at least four dams downstream of the sampling point in China, as well as by other dams in Myanmar, such as the Shweli I Cascade. According to local fishermen, the probability of catching Anguilla nebulosa has decreased considerably. We speculate that individuals isolated by cascade dams, such as the specimen collected in 2014 , can never return to the ocean to complete their breeding cycles because the dams were constructed without fish migration passages. Besides diadromous fish, there are also other smaller-scale migrating fish species in the Irrawaddy River. Although no one has ever studied these fish specifically, the impact of dams is worth paying attention to in the future.

Compared with diadromous fish, the negative influence of dams on native river fish was much broader and more serious in the rivers studied. Dams remove turbulent river sections and create calm water bodies, thus affecting flow and temperature regimes, sediment transport, and species communities (Liermann et al., 2012). The most apparent change in fish communities following the introduction of cascade dams in the Daying and Ruili rivers was the succession of species combinations, which gradually changed from lotic/rheophilic species to lentic ones. In the collections, the occurrence of native rheophilic species (Crossocheilus, Labeo, Garra, Glyptothorax, Pseudecheneis, Creteuchiloglanis, Pseudexostoma, Oreoglanis and Exostoma) decreased, with a concomitant increase in species capable of surviving in both lotic and lentic habitats (Danio, Puntius and Schistura), as well as other eurytopic nonnative species such as Cyprinus carpio, Ctenopharyngodon idella, Abbottina rivularis, Pseudorasbora parva, Gambusia affinis, Rhinogobius giurinus and Oreochromis aureus.

\subsection{Spread of non-native fish}

The spread of non-native species by human activity is a serious threat to biodiversity in both the Daying and Ruili rivers. Exotic species can compete with native fish for food, space and other resources, leading to greatly reduced numbers of local species, and even local extinction (Kang et al., 2009). Furthermore, the shift from lotic to lentic environments after dam construction often favors generalist over specialist species, alters assemblages of taxonomic groups and puts endemic species at particular risk of extinction, leading to biotic homogenization (Liermann et al., 2012). The frequent occurrences of non-native fish in the Daying and Ruili rivers might be a good example of these kinds of influences. The succession trends were exacerbated by the miniaturization of 
many native species in traditional fishing such as Tor qiaojiensis, Neolissochilus baoshanensis and Schizothorax meridional (observing the body size of these fishes between past and present), while non-native species such as Cyprinus carpio and Ctenopharyngodon idella now greatly contribute to fish harvesting, especially in the reservoir area. Although we cannot quantify the negative influences of dams and spread of nonnative species on the fish fauna in Daying River and Ruili River at present, the increasing threats to fish assemblages in regard to taxonomic diversity over the last ten years indicates that more attention should be paid to these rivers and similar tributaries in southwest China.

\subsection{Present and future conservation}

\subsubsection{Existing conservation areas}

The construction of natural reserves is an effective approach to preserving endemic fish resources (Cao, 2000). There are two related authorized conservation areas covering the Irrawaddy drainages of China. One is the Binlangjiang Aquatic Germplasm Resource Protection Area, which was established in 2008 in the upper reaches of Daying River, and resized in 2012. This reserve covers an area of $1343.5 \mathrm{hm}^{2}$ and includes several tributaries of Daying River, such as the Dacha, Danzha, Lunma and Guyong rivers. It is a nationallevel aquatic germplasm resource protection area that specifically protects fish in the Irrawaddy River, including Pseudecheneis brachyurus, Pseudexostoma yunnanense, Danio apogon, Tor qiaojiensis, Garra qiaojiensis, Schizothorax meridionalis, Schizothorax malacanthus, Gymnodiptychus integrigymnatus, Schistura polytaenia, Schistura yingjiangensis, Exostoma labiatum, Glyptothorax longicauda and Glyptothorax minimaculatus. The other is the Tongbiguan National Nature Reserve, which was established in 1986, merged with Ruili River Nature Reserve in 2009, resized in 2011, and approved as a national nature reserve in 2013. It covers an area of $516.505 \mathrm{~km}^{2}$, and includes areas of Yingjiang, Longchuan and Ruili counties. Although Tongbiguan National Nature Reserve aims to protect the whole ecosystem, it also provides shelter to many rare and endangered species, as well as endemic fish such as Hemimyzon yinjiangensis (only recorded from this nature reserve). Scientifically managing these conservation areas and maximizing the effect of in situ conservation should be the top priority of fish conservation in both the Daying and Ruili rivers.

\subsubsection{Potential conservation areas}

The Dulong River exhibits the highest percentage of endemic species and lowest ratio of non-native species compositions, albeit with a relatively simple species assemblage. Among the 14 species in Dulong River, three of them (Placocheilus dulongensis, Schizothorax myzostomus and $S$. dulongensis) are endemic to this river and another four species are endemic to the Irrawaddy basin. Although protection of Dulong River will only favor a small number of rheophilic species, based on its high endemism, avoiding hydropower development in Dulong River would still be meaningful in maintaining a natural running tributary in the Irrawaddy River. The possibility of removing the existing cascade dams in both the Daying and Ruili rivers is very low; however, it is feasible to restrict new dams and enforce environmental protection goals in already completed dams.

Previous studies have suggested that tributaries may be useful biodiversity conservation targets when societal reliance on main river alterations prevents restoration (Pracheil et al., 2009). For instance, relatively unaltered tributaries can sometimes fulfill habitat and life-history requirements for largeriver specialist fish after the main river has been altered by dams or other development projects (Pracheil et al., 2013). Furthermore, given that main rivers have already established cascade dams, tributaries often have very limited development value and should not be exploited for further hydropower projects. Many tributaries in the Daying and Ruili rivers are the last shelters of native fish. Integral assessment of the protection values of affiliated tributaries should be promoted and potentially suitable reserves should be determined as another option for the conservation of native species.

\subsubsection{Artificial propagation and release of endangered fish}

Artificial propagation and release of endangered fish are common strategies in decreasing the impacts of dam construction in China. Such measures not only assist in the recovery of wild populations of endemic and rare fish, but also help to overcome technical bottlenecks in developing new and local aquaculture species (Yang et al., 2013). Current conservation policies for freshwater fish in China mainly focus on endangered species and those of economic importance (Kang et al., 2009), such as the nationally protected Acipenser sinensis, Myxocyprinus asiaticus and Sinocyclocheilus grahami, as well as major economic species such as grass, silver, bighead and black carp (Yang et al., 2013). Three species in the Irrawaddy River are endangered and protected species (Table 3 ). The protection of Anguilla nebulosa, the only diadromous fish, needs consideration in regard to migration passages because artificial propagation of eel species is still a global challenge. The other two endangered species, Gymnodiptychus integrigymnatus and Mastacembelus oatesii, should be priority targets in artificial propagation. In addition, traditionally caught endemic fish species, such as Tor qiaojiensis, Poropuntius margarianus, Neolissochilus heterostomus, Garra qiaojiensis, Schizothorax elongatus, Schizothorax meridionalis and Pseudecheneis gracilis, have declined rapidly in recent years, and should be considered and promoted in future conservation.

Acknowledgements. This work was supported by the National Natural Science Foundation of China (31372182 and 31272275), International Collaboration Project of the Chinese Academy of Sciences (GJHZ201317), Gaoligong Shan Biological Survey Project (DEB0103795), and Yunnan Provincial Biodiversity Conservation Special Fund to De-Ping Kong for Fish Surveys in Daying River and Environmental Assessment due to Cascade Dams. We especially thank David Catania, David A. Neely, William Poly, Carl J. Ferraris, Zi-Ming Chen, Jian Yang, Rui Min, Yan-Fei Haung, Yan-E Jiang, Shu-Sen 
M.-L. Yang et al.: Knowl. Manag. Aquat. Ecosyst. (2016) 417, 9

Table 3. List of endangered and protected fish species of the Irrawaddy in China (modified from Chen (2013)).

\begin{tabular}{|l|c|c|c|}
\hline Species name & National or provincial protection & $\begin{array}{c}\text { Status in China Species Red List. } \\
\text { Vol. 1 Red List }\end{array}$ & Status in IUCN Red List \\
\hline $\begin{array}{l}\text { Anguilla nebulosa } \\
\text { Gymnodiptychus integrigymnatus } \\
\text { Mastacembelus oatesii }\end{array}$ & Provincial & EN (endangered) & \\
CR (critically endangered) & EN (endangered) \\
\hline
\end{tabular}

Shu, Tao Qin and the staff of Gaoligongshan nature reserve, Xiaoheishan nature reserve, Tongbiguan nature reserve and Ruilijiang nature reserve for help in collecting specimens, and Li-Na Du for help in checking specimens. We thank Christine Watts, and the two anonymous reviewers for revising the writing of this paper.

\section{References}

Abell R., Thieme M.L., Revenga C., Bryer M., Kottelat M., Bogutskaya N., Coad B., Mandrak N., Balderas S.C. and Bussing W., 2008. Freshwater ecoregions of the world: a new map of biogeographic units for freshwater biodiversity conservation. BioScience, 58, 403-414.

Allan J.D., Abell R., Hogan Z., Revenga C., Taylor B.W., Welcomme R.L. and Winemiller K., 2005. Overfishing of inland waters. BioScience, 55, 1041-1051.

Allen D.J., Molur S. and Daniel A.D., 2010. The status and distribution of freshwater biodiversity in the Eastern Himalaya. Gland, Cambridge, UK, IUCN, Switzerland, and Coimbatore, Zoo Outreach Organisation, India.

Anderson J., 1878. Anatomical and zoological researches: comprising an account of the zoological results of the two expeditions to Western Yunnan in 1868 and 1875 and a monograph of the two cetacean genera, platanista and orcella, Quaritch, London, 861-869.

Anderson M.J., Ellingsen K.E. and McArdle B.H., 2006. Multivariate dispersion as a measure of beta diversity. Ecol. Lett., 9, 683-693.

Anu A. and Sabu T.K., 2007. Biodiversity analysis of forest litter ant assemblages in the Wayanad region of Western Ghats using taxonomic and conventional diversity measures. J. Insect. Sci., 7, ISSN: $1536-2442$.

Cao W.X., 2000. The natural reserve construction of endemic fishes in the upper Yangtze River and its related problems. Resour. Environ. Yangtze Basin, 9, 131-132.

Chen X.Y., 2013. Checklist of fishes of Yunnan. Zool. Res., 34, 281-343.

Chen X.Y. and Neely D.A., 2012. Schistura albirostris, a new nemacheiline loach (Teleostei: Balitoridae) from the Irrawaddy River drainage of Yunnan Province, China. Zootaxa, 3586, 222-227.

Chen X.Y. and Yang J.X., 2003. A systematic revision of "Barbodes"fishes in China. Zool. Res., 5, 377-386.

Chen X.Y., Yang J.X. and Chen Y.R., 1999. A review of the cyprinoid fish genus Barbodes Bleeker, 1859, from Yunnan, China, with descriptions of two new species. Zool. Stud., 38, 82-88.

Chen Y.R., 2006. Fish resources in the reserve. In: Yang Y.M. and Du F. (eds.), Integrated Scientific Studies of Yunnan Tongbiguan Nature Reserve, Yunnan Science and Technology Press., Kunming.

Chen Y.R., Cui G.H., Shao J.J. and Li Q.H., 1988. Three Cyprinid Fishes New to Chinese Fauna. Zool. Res., 9, 439-440.
Chen Z.M. and Yang J.X., 2004. A new species of the genus Tor from Yunnan, China (Teleostei: Cyprinidae). Environ. Biol. Fish, 70, 185-191.

Chen Z.M., Pan X.F., Kong D.P. and Yang J.X., 2006. Fish biodiversity and its distributional characters during winter in the Dulong River Basin, Yunnan, China. Zool. Res., 27, 505-512.

Chen Z.M., Pan X.F., Xiao H. and Yang J.X., 2012. A new cyprinid species, Placocheilus dulongensis, from the upper Irrawaddy system in northwestern Yunnan, China. Zool. Anz., 251, 215-222.

Chu X.L. and Chen Y.R., 1989. The Fishes of Yunnan, China, Part 1 Cyprinidae, Science Press, Beijing, 377 p.

Chu X.L. and Chen Y.R., 1990. The Fishes of Yunnan, China, Part 2, Science Press, Beijing, 313 p.

Clarke K.R. and Warwick R.M., 1998. A taxonomic distinctness index and its statistical properties. J. Appl. Ecol., 35, 523-531.

Clarke K.R. and Warwick R.M., 2001. A further biodiversity index applicable to species lists: variation in taxonomic distinctness. Mar. Ecol. Prog. Ser., 216, 265-278.

Day F., 1869. On the freshwater fishes of Burma, Proceedings of the Zoological Society of London, Wiley Online Library, 614-623.

Dudgeon D., 2011. Asian river fishes in the Anthropocene: threats and conservation challenges in an era of rapid environmental change. J. Fish Biol., 79, 1487-1524.

Dudgeon D., Arthington A.H., Gessner M.O., Kawabata Z.-I., Knowler D.J., Lévêque C., Naiman R.J., Prieur-Richard A.-H., Soto D. and Stiassny M.L., 2006. Freshwater biodiversity: importance, threats, status and conservation challenges. Biol. Rev., 81, 163-182.

Fang F., 2000. Barred Danio species from the Irrawaddy River drainage (Teleostei, Cyprinidae). Ichthyol. Res., 47, 13-26.

Ferraris C.J. and Britz R., 2005. A diminutive new species of Glyptothorax (Siluriformes : Sisoridae) from the upper Irrawaddy River basin, Myanmar, with comments on sisorid and erethistid phylogenetic relationships. Ichthyol. Explor. Fres., 16, 375-383.

Froese R. and Pauly D., 2014. FishBase. World Wide Web electronic publication.

Gallardo B., Gascón S., Quintana X. and Comín F.A., 2011. How to choose a biodiversity indicator - Redundancy and complementarity of biodiversity metrics in a freshwater ecosystem. Ecol. Indic., $11,1177-1184$.

Hall S.J. and Greenstreet S.P., 1998. Taxonomic distinctness and diversity measures: responses in marine fish communities. Mar. Ecol. Prog. Ser., 166, 227-229.

He Y., Wang J., Lek S., Cao W. and Lek-Ang S., 2011. Structure of endemic fish assemblages in the upper Yangtze River Basin. River Res. Appl., 27, 59-75.

Heino J., Mykra H., Hamalainen H., Aroviita J. and Muotka T., 2007. Responses of taxonomic distinctness and species diversity indices to anthropogenic impacts and natural environmental gradients in stream macroinvertebrates. Freshw. Biol., 52, 1846-1861.

Jiang W.S., Du L.N., Jiang Y.E., Yang J.X. and Chen X.Y., 2010. Fish composition, fauna and life history of Ruili River drainage. $J$. Hydroecol., 3, 1-9. 
Jiang Y.E., Chen X.Y. and Yang J.X., 2008. Microrasbora Annandale, a new genus record in China, with description of a new species (Teleostei: Cyprinidae). Environ. Biol. Fish, 83, 299-304.

Kang B., He D.M., Perrett L., Wang H.Y., Hu W.X., Deng W.D. and Wu Y.F., 2009. Fish and fisheries in the Upper Mekong: current assessment of the fish community, threats and conservation. Rev. Fish Biol. Fisher, 19, 465-480.

Kottelat M., 1989. Zoogeography of the fishes from Indochinese inland waters with an annotated check-list. Zologisch Museum, Universiteit van Amsterdam.

Kottelat M., 1990. Indochinese nemacheilines. A Revision of Nemacheiline Loaches (Pisces: Cypriniformes) of Thailand, Burma, Laos, Cambodia and Southern Viet Nam, Druckerei Braunstein, München, $262 \mathrm{p}$.

Kottelat M., 2001. Fishes of Laos. WHT Publications.

Kottelat M., 2003. Nomenclatural status of Crossocheilus burmanicus, C. horai and C. multirastellatus (Osteichthyes: Cyprinidae). Raffles Bull. Zool., 51, 399-402.

Kottelat M., 2004. Botia kubotai, a new species of loach (Teleostei: Cobitidae) from the Ataran River basin (Myanmar), with comments on botiine nomenclature and diagnosis of a new genus. Zootaxa, 401, 1-18.

Kottelat M. and Lim K.K., 1992. A synopsis of the Malayan species of Lepidocephalichthys, with descriptions of two new species (Teleostei: Cobitidae). Raffles Bull. Zool., 40, 201-220.

Kottelat M. and Whitten T., 1996. Freshwater biodiversity in Asia: with special reference to fish. World Bank Technical Paper, 343, $1-59$.

Kullander S.O. and Britz R., 2002. Revision of the family Badidae (Teleostei: Perciformes), with description of a new genus and ten new species. Ichthyol. Explor. Fres., 13, 295-372.

Liermann C.R., Nilsson C., Robertson J. and Ng R.Y., 2012. Implications of dam obstruction for global freshwater fish diversity. BioScience, 62, 539-548.

Limburg K.E. and Waldman J.R., 2009. Dramatic declines in North Atlantic diadromous fishes. BioScience, 59, 955-965.

Mora C., Tittensor D.P. and Myers R.A., 2008. The completeness of taxonomic inventories for describing the global diversity and distribution of marine fishes. Proc. R. Soc. B-Biol. Sci., 275, 149-155.

Mouillot D., Gaillard S., Aliaume C., Verlaque M., Belsher T., Troussellier M. and Do Chi, T., 2005. Ability of taxonomic diversity indices to discriminate coastal lagoon environments based on macrophyte communities. Ecol. Indic., 5, 1-17.

Myers N., Mittermeier R.A., Mittermeier C.G., Da Fonseca G.A. and Kent J., 2000. Biodiversity hotspots for conservation priorities. Nature, 403, 853-858.

Nelson J.S., 2006. Fishes of the World, 4th edition, John Wiley \& Sons, Hoboken, New Jersey, USA.

$\mathrm{Ng}$ H.H., 2004. Two new glyptosternine catfishes (Teleostei: Sisoridae) from Vietnam and China. Zootaxa, 428, 1-12.

$\mathrm{Ng} \mathrm{H.H.} \mathrm{and} \mathrm{Kottelat} \mathrm{M.,} \mathrm{2008.} \mathrm{Glyptothorax} \mathrm{rugimentum,} \mathrm{a}$ new species of catfish from Myanmar and Western Thailand (Teleostei: Sisoridae). Raffles Bull. Zool., 56, 129-134.

$\mathrm{Ng} \mathrm{H.H.} \mathrm{and} \mathrm{Rainboth} \mathrm{W.J.,} \mathrm{2001.} \mathrm{A} \mathrm{review} \mathrm{of} \mathrm{the} \mathrm{sisorid} \mathrm{catfish}$ genus Oreoglanis (Siluriformes: Sisoridae) with descriptions of four new species, Occasional Papers of the Museum of Zoology, the University of Michigan, 1-34.

Oberdorff T., Pont D., Hugueny B. and Porcher J.P., 2002. Development and validation of a fish-based index for the assessment of "river health" in France. Freshw. Biol., 47, 1720-1734.

Oksanen J., Blanchet F.G., Kindt R., Legendre P., Minchin P.R., O’Hara R.B., Simpson G.L., Solymos P., Henry M. and Stevens
H., 2014. Package "vegan”. Community Ecology Package, 2.2-0, $1-280$.

Pan X.F. and Zhou W., 2004. Fish diversity and conservation of the Irrawaddy river in Yunnan,China. China biodiversity conservation and research progress $\mathrm{V}$.

Pracheil B., Pegg M. and Mestl G., 2009. Tributaries influence recruitment of fish in large rivers. Ecol. Freshw. Fish, 18, 603-609.

Pracheil B.M., McIntyre P.B. and Lyons J.D., 2013. Enhancing conservation of large-river biodiversity by accounting for tributaries. Front. Ecol. Environ., 11, 124-128.

R Development Core Team, 2012. R: A language and environment for statistical computing. R Foundation for Statistical Computing, Vienna.

Rashleigh B., 2004. Relation of environmental characteristics to fish assemblages in the upper French Broad River basin, North Carolina. Environ. Monit. Assess., 93, 139-156.

Rogers S.I., Clarke K.R. and Reynolds J.D., 1999. The taxonomic distinctness of coastal bottom-dwelling fish communities of the North-east Atlantic. J. Anim. Ecol., 68, 769-782.

Shan X.H., 2000. Revision of the genus Puntius (Hamilton) from China and discussion on some taxonomic uncertainty of this genus (Pisces: Cypriniformes, Cyprinidae)). Acta Zootaxonomica Sinica, 25, 114-115.

Su R.F., Yang J.X. and Chen Y.R., 2000. A review of the Chinese species of Crossocheilus, with description of a new species (Ostariophysi: Cyprinidae). Raffles Bull. Zool., 48, 215-222.

Vörösmarty C.J., McIntyre P., Gessner M.O., Dudgeon D., Prusevich A., Green P., Glidden S., Bunn S.E., Sullivan C.A. and Liermann C.R., 2010. Global threats to human water security and river biodiversity. Nature, 467, 555-561.

Wikipedia, 2014. Irrawaddy River.

Wu L.Q., 2010. Rivers and lakes in Yunnan, Yunnan Science and Technology Press, Kunming, 246 p.

Xu W.Y., Miao X.J., Qiu J.R., He W.P., Ding S.L. and Li C.H., 2008. Investigative Reporting About Fish Resource of Gongshan Dulong Nationality and NU Nationality Borough County. $J$. Hydroecol., 1, 122-124.

Yang J., Zhen L.P., Chen X.Y. and Yang J.X., 2013. Description of two new species and revision of Schizothorax distributed in the Irrawaddy drainage area in China. Zool. Res., 34, 361-367.

Yang J.X. and Chu X.L., 1990. A new genus and a new species of Nemacheilinae from Yunnan Province, China. Zool. Res., 11, $109-114$.

Yang J.X., Cui G.H. and Chen X.Y., 2002. A new family record of fishes of China, stinging catfish Heteropneustes fossilis. Zool. Res., 23, 14, 30, 60.

Yang J.X., Pan X.F., Chen X.Y., Wang X.A., Zhao Y.P., Li J.Y. and Li Z.Y., 2013. Overview of the artificial enhancement and release of endemic freshwater fish in China. Zool. Res., 34, 267-280.

Yang L.P. and Zhou W., 2011. A review of the genus Mastacembelus (Perciformes, Mastacembeloidae) in China with description of two new species and one new record. Acta Zootaxonomica Sinica, 36, 325-331.

Zhang E., 2005. Garra bispinosa, a new species of cyprinid fish (Teleostei: Cypriniformes) from Yunnan, Southwest China. Raffles Bull. Zool., 9-15.

Zhang E., 2006. Garra rotundinasus, a new species of cyprinid fish (Pisces: Teleostei) from the upper Irrawaddy River basin, China. Raffles Bull. Zool., 54, 447-453.

Zhang E. and Chen Y.Y., 2002. Garra tengchongensis, a new cyprinid species from the upper Irrawaddy River basin in Yunnan, China (Pisces: Teleostei). Raffles Bull. Zool., 50, 459-464. 
Zhang E. and Chen Y.Y., 2006. Revised diagnosis of the genus Bangana Hamilton, 1822 (Pisces: Cyprinidae), with taxonomic and nomenclatural notes on the Chinese species. Zootaxa, 1281, $41-54$.

Zhang Y., Lu Y.Q., Guo F.Q., Hu S.J. and Cong P.T., 2014. The fish diversity changes in Huizhou Reach of the Dongjiang River during more than 30 years based on species check-list of fish. China Environ. Sci., 34, 1293-1302.

Zhao W.C., He D.M., 1993. Hydrologic characteristics and water resources development in Drungjiang basin. Yunnan Geogr. Environ. Res., 5, 78-87.

Zhou W., Zheng L.P., Li M.H., Fu Q. and Zhang Q., 2006. Fish diversity of two branches of the Irrawaddy River in Yunnan with a preliminary discussion differentiation of river systems, China biodiversity conservation and research progress VII.
Zhou W., Li X. and Yang Y., 2008. A review of the catfish genus Pseudecheneis (Siluriformes: Sisoridae) from China, with the description of four new species from Yunnan. Raffles Bull. Zool., 56, 107-124.

Zhou W., Li X. and Thomson A.W., 2011. A new genus of glyptosternine catfish (Siluriformes: Sisoridae) with descriptions of two new species from Yunnan, China. Copeia, 2011, 226-241.

Zintzen V., Anderson M.J., Roberts C.D. and Diebel C.E., 2011. Increasing variation in taxonomic distinctness reveals clusters of specialists in the deep sea. Ecography, 34, 306-317.

Ziv G., Baran E., Nam S., Rodríguez-Iturbe I. and Levin S.A., 2012. Trading-off fish biodiversity, food security, and hydropower in the Mekong River Basin. Proc. Natl. Acad. Sci. USA, 109, $5609-5614$

Cite this article as: M.-L. Yang, W.-S. Jiang, W.-Y. Wang, X.-F. Pan, D.-P. Kong, F.-H. Han, X.-Y. Chen and J.-X. Yang, 2016. Fish assemblages and diversity in three tributaries of the Irrawaddy River in China: changes, threats and conservation perspectives. Knowl. Manag. Aquat. Ecosyst., 417, 9. 